\title{
Journal of Thermal Spray Technology Volume 19 Best Paper Awards
}

The Journal of Thermal Spray Technology (JTST) is delighted to announce the winners of the JTST Volume 19 Best Papers Awards, as chosen by an international committee of expert judges. The awards were presented to the winning authors at the International Thermal Spray
Conference \& Exposition 2011, in Hamburg, Germany.

The Editorial Committee and International Board of Review of the journal believe it is important to evaluate the quality of engineering and scientific contributions published in JTST and to provide recognition of

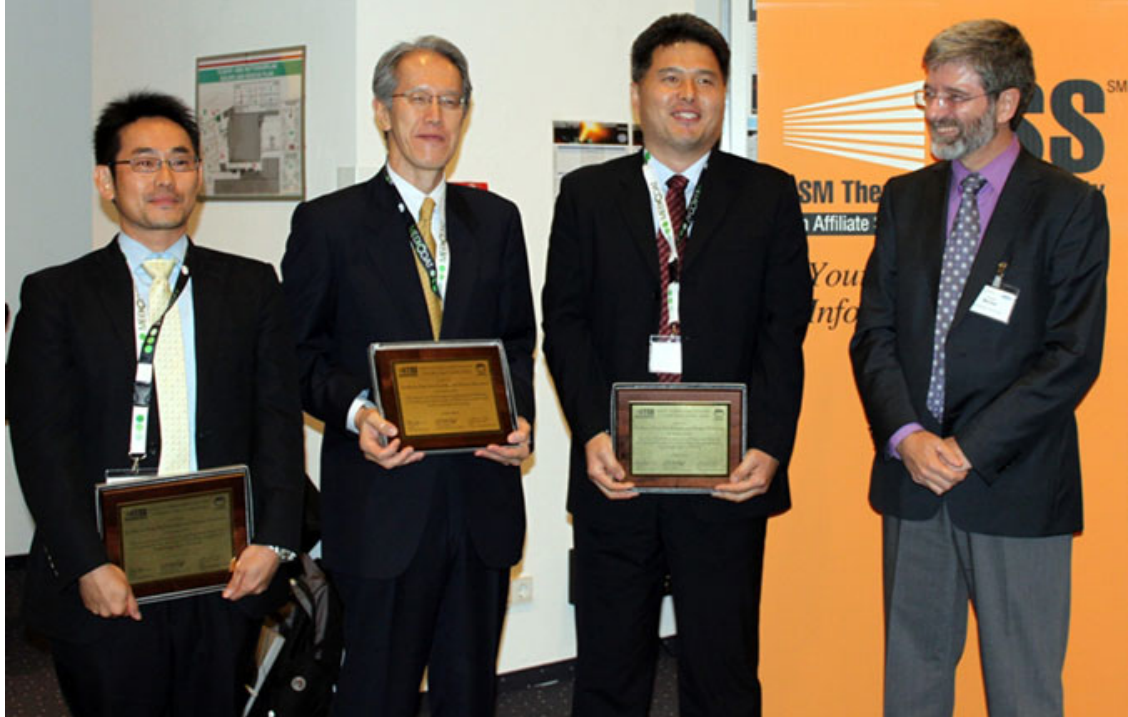

Journal of Thermal Spray Technology editor Christian Moreau (right) presents the JTST Volume 19 Best Paper Award to (from left) Makoto Watanabe, Seiji Kuroda, and KeeHyun Kim for their paper "Microstructural Development and Deposition Behavior of Titanium Powder Particles in Warm Spraying Process: From Single Splat to Coating.'

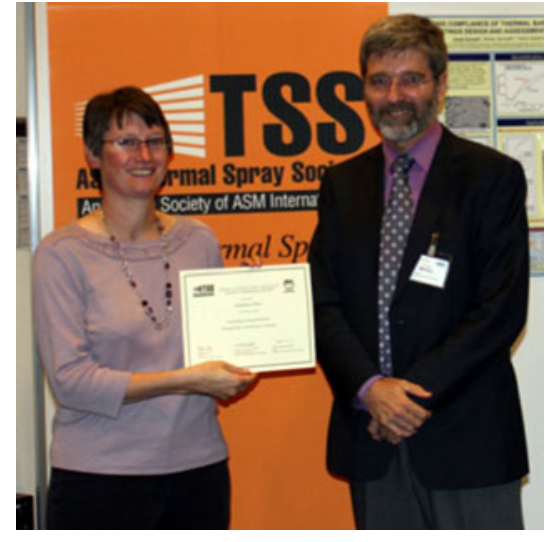

JTST Editor Christian Moreau presents the JTST Volume 19 Best Paper Honorable Mention for the paper "Assessing Coating Reliability Through Pore Architecture Evaluation" by Shiladitya Paul. Dr. Paul's colleague Heidi Lovelock (left) accepted the award on behalf of the author.

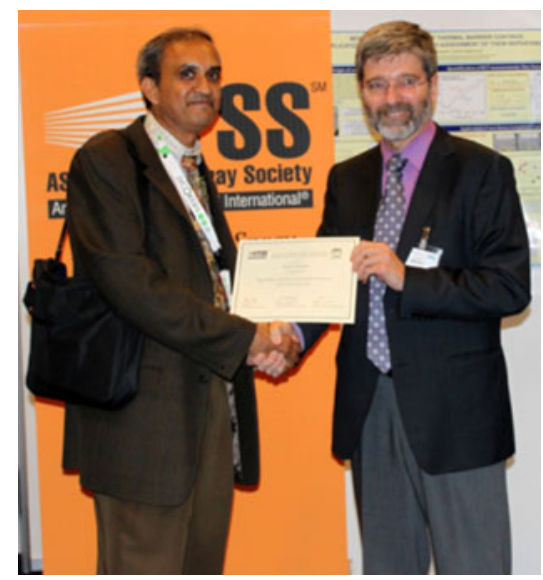

The Outstanding Review Paper Citation was presented by Christian Moreau to Sanjay Sampath (left) for his paper "Thermal Spray Applications in Electronics and Sensors: Past, Present, and Future.' excellent work and its publication. Each paper is reviewed and evaluated on its merits for scientific and engineering content, originality, and presentation style. The following papers are recognized as outstanding and the authors received awards of recognition for their excellent publications.

The Journal of Thermal Spray Technology Volume 19 Best Paper Award:

"Microstructural Development and Deposition Behavior of Titanium Powder Particles in Warm Spraying Process: From Single Splat to Coating" by KeeHyun Kim, Seiji Kuroda, and Makoto Watanabe, Hybrid Materials Center, National Institute for Materials Science (NIMS)

The Journal of Thermal Spray Technology Volume 19 Best Paper Honorable Mention Award:

“Assessing Coating Reliability Through Pore Architecture Evaluation" by Shiladitya Paul, University of Cambridge

The Journal of Thermal Spray Technology Volume 19 Outstanding Review Paper Citation:

"Thermal Spray Applications in Electronics and Sensors: Past, Present, and Future" by Sanjay Sampath, Center for Thermal Spray Research, Stony Brook University

The international committee of judges, led by Dr. Roland Seals, chair of the Journal of Thermal Spray Technology Best Paper Subcommittee, is as follows: Arvind Agarwal, David Bucci, Andrew Gouldstone, Jan Ilavsky, George Kim, Anand Kullkarni, Chang-Jiu Li, Jiri Matejicek, Tim McKechnie, Lech Pawlowski, Luc Pouliot, James Ruud, Igor Sevostianov, Philip Shipway, Richard Schmid, Yoshiki Tsunekawa, Anirudha Vaidya, Alfredo Valarezo, Joel Voyer, and Petri Vuoristo.

Congratulations are extended to the winning authors from the JTST Editorial Board and the ASM Thermal Spray Society Executive Board of Directors. 